\title{
ATITUDES LINGUÍSTICAS DOS RIKBAKTSA: DISCURSO PÚBLICO SOBRE A LÍNGUA*
}

\author{
Mileide Terres de Oliveira*
}

\begin{abstract}
RESUMO: Neste trabalho trazemos o povo Rikbaktsa, habitantes de 35 comunidades indígenas situadas no noroeste do Estado de Mato Grosso. A proposta de nossa pesquisa é de cunho sociolinguístico, em que analisamos as atitudes linguísticas dos Rikbaktsa a partir da situação de contato entre a língua rikbaktsa e o português, em que a atitude linguística consiste no discurso público sobre a língua. Para 0 referido trabalho, enfatizamos 0 discurso público sobre a língua a partir de uma pesquisa bibliográfica e coleta de dados, realizada por meio de um questionário fechado aplicado, a 30 colaboradores bilíngues rikbaktsa/português. Dos resultados encontrados, enfatizamos que a educação indígena é um mecanismo de auxílio para a preservação do idioma nativo, além da formação de professores indígenas capacitados para ministrarem aulas nas aldeias e consequentemente preservar a sua cultura.
\end{abstract}

PALAVRAS-CHAVE: Língua rikbaktsa; Sociolinguística; Atitudes linguísticas.

\section{LINGUISTIC ATTITUDES OF THE RIKBAKTSA: PUBLIC DISCOURSE ON THE LANGUAGE}

ABSTRACT: The Rikbaktsa people, composed of 35 indigene communities in the northwestern region of the state of Mato Grosso, Brazil, are analyzed. Current sociolinguistic research investigates the linguistic attitudes of the Rikbaktsa people in their contact between the Rikbaktsa language and Portuguese, where the linguistic attitude consists in the public discourse on the language, underscored by a bibliographic research and data collection undertaken in a closed questionnaire applied to 30 bilingual Rikbaktsa/Portuguese collaborators. Results show that indigene education is a mechanism for the preservation of the language and the formation of native teachers capable of teaching in the village schools, with the subsequent conservation of their culture.

KEYWORDS: Rikbaktsa language; Sociolinguistics; Linguistic attitudes.

\section{INTRODUÇÃO}

0 Brasil é um país que se caracteriza pela sua diversidade linguística e cultural: em seu território são reconhecidas cerca de 180 línguas nativas e mais de 220 etnias (RODRIGUES, 1994). Diante desta diversidade étnica, destacamos, neste trabalho, a situação de diversidade linguística e cultural vivenciada pela etnia Rikbaktsa, situada no noroeste do Estado de Mato Grosso, próxima aos municípios de Brasnorte, Cotriguaçu e Juara, em 34 comunidades indígenas com cerca de 1.411 pessoas, de acordo com o Instituto Brasileiro de Geografia e Estatística (IBGE, 2010). A língua falada pelos rikbaktsa leva o mesmo nome de sua etnia. Tal língua é, geneticamente, classificada como pertencente ao tronco linguístico macro-jê (BOSWO0D, 1971; RODRIGUES, 1994). Os falantes rikbaktsa estão em contato com a língua oficial brasileira, o português, a qual vem cada vez mais influenciando a comunidade indígena, o que resulta também em grandes mudanças na vida social e cultural

\footnotetext{
Este artigo consiste nos resultados obtidos pelo projeto de pesquisa intitulado: Atitudes linguísticas das relações de contato entre rikbaktsa $\mathrm{e}$ português (Aprovado no edital 036/2016 PROPES/IFMT). Além disso, contou com apoio financeiro de recursos advindos do Instituto Federal de Educação, Ciência e Tecnologia de Mato Grosso (IFMT).

* Doutoranda do Programa de Pós-Graduação Stricto sensu em Linguística pela Universidade Estadual de Campinas (UNICAMP). Docente efetiva do Ensino Básico, Técnico e Tecnológico/LIBRAS do Instituto Federal de Mato Grosso (IFMT) campus Juína (MT), Brasil.

E-mail: mileide.oliveira@jna.ifmt.edu.br
} 
desse povo. A presente pesquisa busca analisar as atitudes linguísticas dos rikbaktsa frente à situação de contato linguístico que se dá entre a sua língua nativa $e$ a língua oficial, o português, por meio do aporte teórico sociolinguístico, considerando as atitudes linguísticas a partir de Schilieben-Lange (1993).

\subsection{OS RIKBAKTSA}

Para além da denominação "Rikbaktsa" encontram-se algumas denominações atribuídas ao povo e sua língua: os rikbaktsa eram denominados "canoeiros" pelos seringueiros, ela grande habilidade no manejo de canoas, e "orelhas de pau", uma referência aos "batoques que usam nos lóbulos das orelhas" (SILVA, 2005, p. 02). Boswood (1973, p. 01) afirma que também eram conhecidos como "Aripaktsa" e "Erigbaktsa".

Os rikbaktsa vivem em três terras indígenas na mesma região: a Terra Indígena Japuíra, a TI Escondido e a TI Erikpaktsa, num território de cerca de 320 mil hectares de mata amazônica de acordo com o Instituto Socioambiental (ISA, 2014). No site do ISA (2014) consta que a TI Japuíra possui cerca de 154.843 ha e uma população de 215 rikbaktsa. A TI Erikpaktsa tem uma população de 676 rikbaktsa, em cerca de 80 ha de mata amazônica. A TI Escondido, por sua vez, possui 169.649 ha e 45 rikbaktsa (idem).

A população rikbaktsa é dividida em duas metades: Arara Amarela (Makwaraktsa) e Arara Cabeçuda (Hazobiktsa), além de outras subdivisões em clãs ${ }^{3}$. Esta divisão inclui elementos da flora e fauna, assim como não-humanos (ARRUDA, 1992). Cada metade possui a divisão dos seguintes clãs:

Metade MAKWARAKTSA (arara amarela):

- Makwaraktsa (arara amarela, "puro" amarela, como dizem).

\footnotetext{
3 De acordo com Hahn (1976, p. 96 apud PACINI, 1999, p. 14-15) "os nomes dos clãs seriam não mais que nomes de famílias - patrônimos, nos quais nem todas as relações genealógicas são calculáveis. Isto certamente não esclarece a associação entre os membros de clãs e os animais ou plantas aos quais os nomes dos clãs se referem. Também não esclarece como os clãs se relacionam ideologicamente e de fato".
}

- Tsikbaktsa (arara vermelha).

- Bitsitsiyktsa (fruta silvestre).

- Mubaiknytsitsa (referido ao macaco aranha, quat ).

- Zoktsa ("pau torcido", refere-se a um tipo de árvore).

- Zuruktsa (animal feroz, mítico, aparentado à onça - parini - que hoje não existe mais)

- Wohorektsa (certa árvore).

Metade HAZOBIKTSA (arara cabeçuda):

- Hazobiktsa (arara cabeçuda).

- Umahatsaktsa (figueira).

- Tsuãratsa (macuquinho).

- Tsawaratsa (inajá).

- Bitsiktsa (tucano).

- Buroktsa ( árvore, "pau leiteiro").

- Zerohopyrytsa (jenipapo) (ATHILA, 2006, p. 178).

A caça é típica dos homens e tudo que conseguem durante a caçada é levado para suas esposas que são responsáveis pelo preparo e a distribuição para a família do caçador e para a casa dos homens, o mykyry. Conhecido como um tipo de casa tradicional, o mykyry é feita de palha de vários coqueiros como o babaçu, inajá e açaí, e as paredes são feitas de lasca destes coqueiros. As mulheres são proibidas de frequentar o mykyry, ou seja, apenas os homens podem utilizá-la, pois é neste local que eles trabalham, confeccionam seus artesanatos, arcos e flechas, entre outros tipos de trabalhos (idem).

Os rikbaktsa comem peixe e apreciam as aves, tais como gavião de penacho, araras, papagaios, macuco, marreco, entre outras, e também aproveitam as asas para a confecção dos artesanatos. A coleta de castanhas-do-pará geralmente é realizada pelas mulheres, que fazem mingau, bolo, pães e óleo para fritura. 0 mel também é muito consumido pelos rikbaktsa, utilizado para adoçar os alimentos, principalmente as chichas, tipo de bebida fermentada com banana, milho, batatas ou cará (ibdem). 
Existe um ritual na etnia rikbaktsa conhecido como ritual da chegada, quando um indígena ou não indígena chega na aldeia é oferecido chicha e comida para ele, sendo uma forma de acolhida, pois compartilhar 0 alimento é um gesto de respeito pelo outro, 0 anfitrião oferece ao visitante uma das coisas mais valiosas para os rikbaktsa: a sua própria comida (PACINI, 2015).

Há dois fenômenos naturais da região matogrossense: a seca e a chuva. Nestes períodos distintos os rikbaktsa realizam várias tarefas como, por exemplo, na seca (período que vai de maio a outubro) é o momento em que as chuvas são reduzidas, e os indígenas procuram lumas e haste para confeccionar suas flechas. Além disso, eles aproveitam a seca para realizar a derrubada da mata para o plantio, e durante este período promovem pequenas festas. Na época da chuva (que compreende novembro a maio) fazem 0 plantio das roças que pertencem a determinados grupos familiares. Geralmente plantam batatas, mandiocas, milho, bananas, frutas cítricas e algodão para tecer as redes. Em ambas as épocas (seca e chuva), os indígenas gostam de caçar e pescar.

Os pajés são importantes para os rikbaktsa, orientam o povo e possuem muito conhecimento, sobretudo dos rituais e das ervas medicinas, eles são curandeiros e se comunicam com os espíritos e deuses para ajudar o povo e conservar suas tradições (PEREIRA, 2015). No ano de 2014 um grande ancião do povo rikbaktsa faleceu, Geraldino Patamy. Em comunicação pessoal os indígenas relatam que ficaram dias velando 0 corpo de Geraldino e realizando o ritual da lamentação, e junto com seu caixão foram deixados alguns artesanatos, produzidos por ele mesmo. Os rikbaktsa relatam que Geraldino era tão respeitado que seu batoque na orelha era o maior entre todos os mais velhos, pois além de promover a preservação dos costumes rikbaktsa, sempre organizava as festas e ensinava as tradições aos mais jovens.

\section{DISCURSO PÚBLICO SOBRE A LÍNGUA (SCHLIEBEN-LANGE, 1993)}

0 discurso público sobre a língua, diz respeito ao falar que retoma outros falares do mundo, ou seja, falamos outros discursos que já foram ditos em outro momento. Diante desta definição, analisamos qual a língua que os entrevistados preferem usar para escrever, tal qual mais bonita, feia, fácil, difícil, gostam mais de falar, falam mais no dia a dia; se há rikbaktsa que rejeitam a própria língua; se sentem vergonha de falar a língua nativa; se os colaboradores acham importante que seus filhos aprendam rikbaktsa; se eles acham que a língua rikbaktsa esta desaparecendo e se há algum trabalho de preservação da língua rikbaktsa na aldeia.

Para alcançarmos tal propósito, utilizamos a técnica de coleta de dados que envolve a observação e compreensão seletiva por parte do investigador, razão pela qual utilizamos a técnica de elicitação, por meio de um questionário. A escolha de um questionário guia como instrumento de pesquisa nos possibilitou comparar um conjunto de respostas e analisar, sobretudo, as atitudes linguísticas dos indígenas, de acordo com a geração pertencente.

Elaboramos uma ficha pessoal com dados dos colaboradores, em seguida, aplicamos um questionário fechado com perguntas sobre 0 contato linguístico (rikbaktsa/português), as possíveis situações de interação que acontecem nos cinco domínios linguísticos sugeridos por Fishman (1995): Domínio familiar, religioso, vizinhança (aldeia), escolar e trabalho. Além disso, buscamos descrever 0 uso da língua rikbaktsa e do português no dia a dia.

Este trabalho limitou-se à coleta entre moradores das aldeias: Primavera, Cerejeira, Pé de Mutum, Aldeia Velha, Barranco Vermelho e Jatobá. Entretanto, enfatizamos que a coleta de dados foi realizada no município de Juína - MT, nos momentos em que os indígenas saem de suas aldeias e vão para a cidade.

Entrevistamos 30 colaboradores indígenas 
rikbaktsa seguindo uma prévia estratificação que leva em conta três distintas gerações (de faixa etária também distinta). Das três gerações, o grupo da primeira geração contempla indígenas acima de 48 anos; a segunda geração é composta pelos colaboradores entre 38 e 47 anos; e a terceira geração na faixa etária entre 18 e 37 anos $^{4}$. De acordo com os dados esboçados, organizamos o Quadro 1:

Quadro 1. Estratificação dos colaboradores

\begin{tabular}{|l|l|c|}
\hline \multicolumn{1}{|c|}{ Origem } & \multicolumn{2}{c|}{ Sexo do falante } \\
\hline $1^{\text {a }}$ geração: acima de 48 anos & Homem & Mulher \\
\hline $2^{\mathrm{a}}$ geração: 38-47 anos & Homem & Mulher \\
\hline $3^{\mathrm{a}}$ geração: $18-37$ anos & Homem & Mulher \\
\hline
\end{tabular}

Para compreensão das análises nos referimos aos colaboradores como $1.1 \mathrm{M}, 1.2 \mathrm{H}$, etc., sendo que 0 primeiro número se refere à geração pertencente e 0 segundo refere se ao número do colaborador. Como por exemplo, o entrevistado $1.2 \mathrm{H}$ se refere a um indígena da primeira geração, o segundo colaborador, sendo um homem $(H)$, enquanto a colaboradora $1.1 \mathrm{M}$ trata-se da primeira geração, a primeira colaboradora, sendo uma mulher (M).

\section{ANÁLISE LINGUíSTICA}

Neste tópico, tratamos das atitudes linguísticas dos rikbaktsa manifestadas diante da própria língua nativa (rikbaktsa) e a do outro (português), a partir do discurso público sobre a língua (SCHLIEBENLANGE, 1993), em que a variedade de fala utilizada pode possuir valores de juízo, tanto positivos, como negativos, relacionada ao modo do outro falar e do seu próprio modo de falar. Para atingirmos tal propósito, perguntamos aos colaboradores qual a língua que eles acham mais bonita, todos responderam o rikbaktsa; abaixo trazemos algumas respostas:

\footnotetext{
${ }_{4}$ Todos os colaboradores assinaram o TCLE (Termo de Consentimento Livre e Esclarecido). Informamos que esta pesquisa foi aprovada pela CEP (Comitê de Ética - IFMT) CAAE: 57505616.0.0000.8055-Número do parecer: 1.546 .318 .
}

1.1 M: Rikbaktsa, porque é a língua da minha etnia.

$1.2 \mathrm{H}$ : Rikbaktsa.

$1.3 \mathrm{M}:$ A língua do meu povo, rikbaktsa.

$1.4 \mathrm{H}$ : A língua do meu povo.

$1.5 \mathrm{M}: 0$ meu idioma, rikbaktsa.

$1.6 \mathrm{H}$ : Rikbaktsa. Por causa da tradição, música, festa de tudo que rikbaktsa tem eu acho mais bonita.

$2.11 \mathrm{H}: 0$ nosso idioma.

2.12 M: Rikbaktsa porque é mais bonita, é a língua do meu povo.

$2.13 \mathrm{H}: 0$ idioma, claro, é a língua do meu povo, eu acho mais bonita.

$2.18 \mathrm{M}$ : Rikbaktsa.

$2.19 \mathrm{H}$ : A língua do meu povo, rikbaktsa é mais bonita.

2.20 M: Rikbaktsa. Porque eu acho bonito falar.

$3.23 \mathrm{H}$ : Rikbaktsa, claro, é o nosso idioma

3.24 M: Rikbaktsa, porque a minha língua é importante pra mim.

$3.25 \mathrm{H}:$ Rikbaktsa, claro, é o nosso idioma.

3.26 M: Rikbaktsa, o meu idioma.

$3.27 \mathrm{H}$ : Eu acho mais bonita a língua rikbaktsa.

$3.30 \mathrm{M}$ : A língua rikbaktsa é mais bonita.

A língua rikbaktsa é mais apreciada que 0 português. A expressão mais bonita é uma atitude que reflete 0 sentido de pertencer à identidade étnica indígena, e é manifestado pela atitude positiva, ao considerar a língua rikbaktsa mais bonita que 0 português, mesmo que a predominância da fala seja da língua portuguesa. Quando todos afirmam rikbaktsa, demonstram 0 reconhecimento da língua rikbaktsa como o idioma próprio da etnia: língua do meu povo, língua da minha etnia, nosso idioma, minha língua é importante pra mim. Nas respostas, a valorização da língua rikbaktsa está relacionada à representatividade da etnia rikbaktsa; 0 seu povo é considerado o mais prestigiado para 0 entrevistado, consequentemente a sua língua é a mais prestigiada no julgamento de valor do colaborador, pois a língua rikbaktsa é importante para a etnia: 
$1.5 \mathrm{M}:$ A arma que hoje nós temos é o nosso idioma materno.

1.6 H: Eu sinto que a língua hoje é de extrema importância, porque é nossa identidade, a cultura da gente é valorizada [...].

Os pronomes são argumentos de identificação cultural e linguística, conforme expresso no Quadro 2:

Quadro 2. Atitudes manifestadas

\begin{tabular}{|l|}
\hline \multicolumn{1}{|c|}{+ rikbaktsa } \\
\hline Minha etnia \\
\hline Língua do meu povo \\
\hline Nosso idioma \\
\hline Nossa identidade \\
\hline
\end{tabular}

A utilização dos pronomes pessoais que indicam posse: minha, meu, nosso, nossa, reafirmam a identificação dos rikbaktsa enquanto indígenas, pertencentes a etnia rikbaktsa e que valorizam a sua cultura e a sua língua.

Weinrich (2011) afirma que atitudes positivas referentes a uma língua podem ser analisadas pelo fato de ser a língua nativa de sua comunidade linguística. 0 autor afirma que os falantes desenvolvem um apego emocional com o idioma de origem, o qual, muitas vezes receberam as primeiras formações ${ }^{5}$. Não somente no domínio familiar, mas também nos outros domínios linguísticos, em que os jovens possuem contato com seus costumes tradicionais que fazem relembrar todo sentimento de pertença a uma etnia, com uma história de luta e resistência de sua cultura, frente às invasões alheias. A importância da língua nativa não pode ser igualada ao uso de qualquer outra língua, para o falante nativo, a sua língua é sempre a mais rica, mais bonita e mais valorizada, o sentimento de pertencimento a uma identidade étnica é mais forte que a preferência pela língua do outro.

Indagamos aos colaboradores se eles acham

\footnotetext{
${ }^{5}$ Do texto original: "another source of positive attitudes toward a language is to be found in its very status as a mother-tongue. Most persons develop an emotional, pre-rational attachment to the language in which they receive their earliest and most fundamental training in semiotic behavior" (WEINRICH, 2011, p. 7).
}

importante ensinar o idioma nativo aos seus filhos e se eles saberiam ensiná-los. Diante disso, expomos alguns depoimentos:

1.5 M: Sim, eu acho importante e eles sabem um pouco.

$1.6 \mathrm{H}$ : Sim, eu ensinei eles e algumas coisa eles aprenderam.

$1.7 \mathrm{M}$ : Sim, eu tento ensina pra eles.

$1.8 \mathrm{H}$ : Eu ensino meus filhos e netos e quero que eles ensinem os filhos deles também.

1.9 M: Sim, eu ensino eles, tem que sabe o idioma.

$1.10 \mathrm{H}$ : Sim, mas eles tem que ir atrás para aprender, buscar o aprendizado.

2.14 M: Eu acho importante e quero que todos aprendam, e eu vou ajuda eles a aprende.

$2.15 \mathrm{H}$ : Sim, na aldeia eu falo do jeito das pessoas da aldeia e eu ensino rikbaktsa.

2.16 M: Sim, é importante, aquilo que eu sei eu ensino desde pequeno.

$2.17 \mathrm{H}$ : Eu quero que eles aprendam e eu vou ensina o que eu sei pra eles.

2.18 M: Sim, eu tô tentando ensina pra eles.

$2.19 \mathrm{H}$ : Eu ensino meus filhos e quero que eles aprendam o nosso idioma.

$3.21 \mathrm{H}$ : Sim eu quero que eles aprendam.

3.22 M: Eu quero que ele aprenda, o que eu sei eu vou ensinar pra ele, mas eu queria aprende de tudo para ensinar pra ele, mas se eu falar direto no idioma com ele, ele vai prende melhor que eu.

Eles falam que criança é melhor pra aprender que adulto.

$3.23 \mathrm{H}$ : Eu quero que eles saibam fala o nosso idioma, e eu vou ensinar o que eu sei pra eles.

3.28 M: Eu vou ensinar, mas minha mãe também disse que me ajuda e eu quero que ele fale na língua do nosso povo.

$3.29 \mathrm{H}:$ Sim, eu quero que fale o nosso idioma e eu vou ajudar sim.

3.30 M: Eu quero que eles aprendam e minha família ensina, na escola ele também vai aprende. 
Todas as gerações querem que seus filhos aprendam rikbaktsa e afirmam que pretendem ensinar. 0 grupo da primeira geração relata que eles têm que ir atrás para aprender, esta afirmação retoma a tradição rikbaktsa do rodeio, o mykyry, em que os homens se reuniam e trocavam experiências e os mais novos aprendiam com os mais velhos. Mas esta iniciativa é espontânea, os próprios indígenas demonstram interesse em compartilhar estes momentos com os anciãos e assim, adquirir o conhecimento. De acordo com Athila (2006, p. 258), "algumas vezes crianças de ambos os sexos acompanham seus pais e avôs nas atividades do mykyry. Eles aproveitam a oportunidade para ensinar-Ihes alguma tarefa". Os mais velhos são incentivadores dos costumes indígenas e transmitem para os jovens nas aldeias.

0 grupo da segunda geração também ensina seus filhos o idioma nativo, na aldeia eu falo do jeito das pessoas da aldeia, o jeito de falar na aldeia refere-se aqueles momentos em que a interação entre rikbaktsa acontece pela língua nativa, geralmente em conversas com os mais velhos que se comunicam mais no idioma nativo.

0 grupo da terceira geração, apesar de nem todos terem filhos ainda, também querem que a futura geração aprenda o idioma do seu povo, e que desde pequeno possa aprender a língua rikbaktsa: eles falam que criança é melhor para aprender que adulto.

Os argumentos descritivos ou avaliativos do discurso público são os estereótipos (SCHLIEBENLANGE, 1993), que consistem nos julgamentos de "bonito" ou "feio", "melhor" ou "pior" etc. Perguntamos aos colaboradores qual a língua mais feia e todos afirmaram ser a língua portuguesa, vejamos algumas respostas:

$1.1 \mathrm{M}:$ Português.

$1.2 \mathrm{H:} 0$ português.

$1.3 \mathrm{M:} 0$ português mesmo.

$1.4 \mathrm{H}: 0$ português.

$1.5 \mathrm{M}$ : Português é mais feia.

$1.6 \mathrm{H}:$ Português, mas tem muitos termos que muitas vezes lá na frente é outro termo e você acaba não entendo o significado daquela palavra, ela é complicada, mas o rikbaktsa é só um sentido.

$2.11 \mathrm{H}$ : Eu acho português mais feio. $2.12 \mathrm{M}$ : Português é mais feio, porque não é o nosso idioma.

$2.13 \mathrm{H}$ : Português, porque se a gente fala errado todo mundo percebe.

$2.14 \mathrm{M}$ : Eu acho o português mais feio. $2.15 \mathrm{H}$ : 0 português, porque não é do nosso povo.

$2.16 \mathrm{M}$ : Acho mais feio o português.

$3.23 \mathrm{H}$ : Português porque não é o nosso idioma mesmo.

$3.24 \mathrm{M}$ : Português, porque não é nossa língua.

$3.25 \mathrm{H}$ : Eu acho que o português é mais feio porque não é nossa língua.

$3.26 \mathrm{M}$ : Português, porque não é nosso idioma.

3.27 H: Português é mais feio, não é o idioma na nossa etnia.

$3.28 \mathrm{M}$ : Português porque não é do nosso povo.

Os rikbaktsa sabem o português, mas acham feia, por não ser o idioma nativo, por ser complicado e ainda, se fala errado todo mundo percebe. Como 0 português não é a língua da etnia rikbaktsa, acham o idioma nativo mais bonito e, consequentemente, a língua do outro: 0 português, mais feia. Nesta perspectiva, a função da linguagem consiste em transmitir informações sobre os falantes e estabelecer relações sociais, contexto em que o falante consegue descrever o seu falar a partir do falar do outro, ou seja, pelas semelhanças e diferenças que estabelecem entre as duas línguas em contato (GIMENES-MORALIS, 2000). Deste modo, em uma determinada comunidade de fala, as atitudes linguísticas exercem influências sobre 0 comportamento linguístico do falante. Perguntamos qual a língua mais difícil, obtivemos as seguintes respostas:

$1.1 \mathrm{M}: 0$ português, muita regra, muito termo.

$1.2 \mathrm{H}$ : Português

$1.7 \mathrm{M}$ : Português, tem muita regra.

$1.8 \mathrm{H}$ : 0 português, é complicado.

1.9 M: Português, difícil interpretar.

$1.10 \mathrm{H}$ : Português, tem muitos termos. 
$2.11 \mathrm{H}$ : Rikbaktsa, é difícil escrever. $2.12 \mathrm{M}$ : Eu acho difícil rikbaktsa, porque a escrita é difícil.

$2.13 \mathrm{H}$ : Rikbaktsa, escrever e falar, ela é uma língua muito rápida, tem que falar muito ligeiro. As vezes você não entende, para escrever é complicado.

2.14 M: Rikbaktsa eu acho mais difícil.

$2.15 \mathrm{H}$ : Rikbaktsa é mais difícil.

2.16 M: Eu acho rikbaktsa.

3.25 H: Rikbaktsa, porque é difícil fala.

3.26 M: Rikbaktsa eu acho que é bem mais difícil.

$3.27 \mathrm{H}$ : Eu acho que o rikbaktsa, porque é complicado pra escreve.

$3.28 \mathrm{M}$ : Rikbaktsa.

3.29 H: Eu acho que é bem mais difícil rikbaktsa.

$3.30 \mathrm{M}$ : Rikbaktsa, porque eu não aprendi a fala desde pequena, se eu dominasse bem a minha língua eu não teria tanta dificuldade para falar.

Em contrapartida, interrogamos qual a língua eles acham mais fácil, alguns nos responderam:

1.3 M: 0 Rikbaktsa, eu gosto do idioma e acho mais fácil.

$1.4 \mathrm{H}$ : O idioma mais fácil, o português é muito difícil, muito difícil escrever, tem muita regra.

2.18 M: Português, mais fácil, a gente acha bonito.

2.19 H: Hoje eu acho o português, porque tenho mais contato, tudo o que eu faço é em português.

3.28 M: 0 português, porque a gente aprende desde criança, já aprende a falar o português

$3.29 \mathrm{H}$ : 0 português, parece mais fácil que rikbaktsa, eu acho.

0 grupo da primeira geração acha o português mais difícil, principalmente na escrita, na interpretação e ainda relatam que há muita regra, estas respostas refletem 0 monolinguismo existente nesta geração antes do contato com os não-indígenas. A L1 era a língua rikbaktsa, depois aprenderam o português, e de maneira imposta, por isso a facilidade com a língua nativa, que desde pequenos conviveram e aprenderam na aldeia e apesar de ficar anos no Internato, 0 idioma nativo faz parte da cultura dos rikbaktsa.

0 grupo da segunda geração acha mais difícil a língua rikbaktsa, por ser diferente do português, sendo que no dia a dia usam mais o português, tanto na fala como na escrita, por isso acham mais fácil. 0 colaborador $2.19 \mathrm{H}$ ainda diz: tudo o que eu faço é em português, ou seja, no cotidiano, suas tarefas e atividades são desenvolvidas em língua portuguesa, 0 mesmo colaborador relata sobre a língua rikbaktsa: Às vezes você não entende, para escrever é complicado. 0 uso linguístico do grupo da segunda geração acontece mais em português, por isso a fala e para eles a escrita em rikbaktsa é difícil, pois no cotidiano não utilizam com frequência o idioma nativo.

0 grupo da terceira geração acha mais difícil a língua rikbaktsa, a colaboradora $3.28 \mathrm{M}$ afirma que acha difícil o idioma porque eu não aprendi a falar desde pequena, esta geração tem como L1 0 português, e o idioma nativo é aprendido no domínio familiar e escolar, mas eles aprendem a língua portuguesa desde pequenos, e é a língua mais usada, por isso acham mais fácil e possuem mais afinidade com a língua que utilizam com mais frequência.

Quando pedimos para os entrevistados qual a língua eles gostam mais, todos respondem rikbaktsa, mas quando interrogados qual a língua que mais falam no dia a dia, é unânime a resposta: português. Se eles preferem o idioma nativo, porque usam mais a língua do outro? Esta era a nossa inquietação enquanto realizávamos 0 questionário.

A partir do entendimento de estereótipo proposto por Schlieben-Lange (1993), que consiste no argumento do discurso público ou daqueles que concorrem entre si, nas respostas ao questionário existe uma atitude compartilhada pela sociedade rikbaktsa, em que a língua nativa, gera avaliações negativas, de vergonha. Interrogamos: "Alguns Rikbaktsa rejeitam a própria língua?" Destacamos abaixo algumas respostas obtidas: 
$1.5 \mathrm{M}$ : Sim. Se não tivesse vergonha as crianças podiam falar no idioma. $1.6 \mathrm{H}$ : Sim. Porque tem medo de falar errado, eu tenho percebido que eles, às vezes, nem tem vergonha mas não sabe a pronúncia da palavra. É porque eles não sabem mesmo, como se conversa no idioma, no sentido que eu percebi na maioria. Muitos não sabem o idioma.

$2.12 \mathrm{M}$ : Sim, alguns jovens não querem falar e muitos não querem aprende, porque tem vergonha de fala o idioma.

$2.13 \mathrm{H}$ : Sim, devido a falta de incentivo dos próprios pais, que dão muita liberdade, assim de viver na cidade e pega todo o costume da sociedade não-indígena.

$3.27 \mathrm{H}$ : Eu acho que tem, acho que sente vergonha do seu próprio idioma, eu não sei porque.

$3.30 \mathrm{M}$ : A gente, às vezes, tem até vergonha de falar, pra não falar errado.

Os mais jovens não falam a língua rikbaktsa, discurso público instaurado acerca da desvalorização da língua nativa perante a língua portuguesa, de maior status na sociedade não indígena. 0 discurso dos colaboradores legitima que apesar de considerarem a língua rikbaktsa a mais bonita, afirmam que muitos se envergonham em falar a própria língua nativa. Temos um conflito que nos leva a refletir quais seriam os motivos desta mudança de atitude/comportamento em relação à própria língua. Existe uma atitude negativa dos colaboradores diante da própria fala quando afirmam: tem vergonha. Trata-se da identidade linguística dos rikbaktsa que se consideram indígenas, acham bonita a sua cultura e língua, mas não utilizam no dia a dia, pois a influência do português é tão grande que ocasiona a vergonha em falar sua língua nativa.

Alguns rikbaktsa estão mais influenciados pela cultura do outro do que pela própria cultura nativa, devido, sobretudo ao convívio na cidade. Por isso, todos os colaboradores afirmam que 0 idioma está se perdendo, sobretudo pelo desuso e o desinteresse dos mais jovens em aprender o idioma nativo. Os colaboradores se auto-avaliam como falantes da língua rikbaktsa e do português, mas o estereótipo que recobre a língua nativa, ou seja, a vergonha que os mais jovens possuem em falar a língua rikbaktsa, faz com que eles busquem afastar-se da estereotipação e deixam de falar a língua rikbaktsa, afirmando ter vergonha de pronunciar o próprio idioma.

Pode-se definir que a

[...] atitude é uma disponibilidade,
uma tendência para agir ou reagir de
um certo modo quando confrontado
com certos estímulos. [...] As atitudes
são reforçadas por crenças (o
componente cognitivo) e geralmente
atraem fortes reações (o componente
emocional) que levarão a formas
determinadas de comportamento (a
componente de tendência expressiva)
(OPPENHEIM, 1966, apud GIMENES-
MORALIS, 2000, p. 38-39).

Essa concepção de Oppenheim (1966, apud GIMENES-MORALIS, 2000) considera o componente emocional como gerador de formas expressivas no comportamento, ou seja, um julgamento de valor. As marcas linguísticas "tem medo de falar errado", "tem vergonha de fala o idioma", "sentem vergonha do seu próprio idioma”, são expressões negativas em relação ao próprio idioma, considerado anteriormente como o "mais bonito", mas agora contradito nas atitudes negativas.

Para explicar os diversos discursos que ocorrem dentro da fala de um indivíduo bilíngue, Schlieben-Lange (1993) realizou uma pesquisa sociolinguística com os moradores da vila de Bagnols-sur-Cèze (sul da França). Com o objetivo de verificar se o occitano ainda era falado nesta vila, suas análises evidenciaram que 0 falante possui um saber sobre a língua, quando reconhece a existência e 0 uso da língua materna na França. Entretanto, há em seu discurso aquilo que é imposto, não há uso da língua occitana na França, como um discurso oficial; e por outro lado temos a língua falada no cotidiano, que é o occitano, preservado na fala entre os parentes e familiares na França (idem, p. 96). 
Os rikbaktsa possuem um saber sobre a língua quando reconhecem o uso da língua nativa nos domínios linguísticos, em situações de interação com falantes do idioma nativo, principalmente os mais velhos e durante os rituais. Contudo, analisamos em suas respostas que os mais jovens não usam a língua rikbaktsa porque têm vergonha de falar o idioma nativo, como um discurso público sobre a língua, pois no dia a dia os mesmos indígenas afirmam que existem momentos em que a língua rikbaktsa é utilizada, mesmo afirmando que o português é mais usado no cotidiano, existem alguns momentos em que a língua rikbaktsa também é usada.

Perguntamos aos colaboradores se a língua rikbaktsa estava desaparecendo.

$1.2 \mathrm{H}:$ Sim, tá desaparecendo porque eu ouço muito pouco.

1.5 M: Sim, tá devagar, mas tá.

$2.13 \mathrm{H}$ : Pra mim tá, porque o jovem de hoje tá falando muito pouco a nossa língua, fala mais português. Muito pouco jovem fala a língua.

2.20 M: Olha eu acho que em certos lugares que não tem pessoas que não incentivam, tá desaparecendo sim.

3.22 M: Sim, poucas pessoas falam e esta desaparecendo mesmo.

$3.23 \mathrm{H}$ : Eu acho que a língua ta morrendo, porque tem pouca gente que fala a língua.

Os indígenas veem que a língua rikbaktsa está desaparecendo porque não se ouve mais 0 idioma nas aldeias. 0 saber sobre a língua como uma atitude linguística, nos domínios linguísticos familiar, vizinhança, escolar, religioso e trabalho, há a predominância do uso da língua portuguesa, e 0 idioma nativo é usado em algumas ocasiões restritas. 0 comportamento linguístico dos rikbaktsa leva a escolha da língua portuguesa na comunicação, pois é a língua que todos entendem, assim a interação acontece de maneira satisfatória.

A atitude linguística também pode ser vista como uma reação diante de uma determinada situação. Neste caso, o contato entre 0 rikbaktsa e 0 português ocasiona reações negativas de rejeição à própria língua nativa, em contrapartida, todos afirmam positivamente que consideram o idioma nativo o mais bonito. Estas reações distintas são influenciadas pela intensa relação de contato entre indígenas e não indígenas, e pela dominação da língua portuguesa. As respostas anteriores sobre o domínio linguístico apresentam que a língua rikbaktsa vem diminuindo seus lugares de predominância e 0 português vem sendo a principal língua usada nas interações. Este deslocamento da língua nativa para a língua oficial, 0 português, reforça as reações negativas em relação ao uso de um idioma em detrimento de outro.

Para Schilieben-Lange (1993, p. 97), a consciência linguística está no campo da heterogeneidade, não pode ser considerado algo homogêneo, definido naturalmente pelo falante. Entretanto, esta heterogeneidade possui uma ligação entre o discurso oficial sobre a língua e aquilo que consiste na experiência cotidiana da língua, ambas as concepções estão interligadas, mas a consciência linguística resultante do falar não é homogênea, e muitas vezes pode ser contraditória. 0 discurso oficial sobre a língua rikbaktsa é que ela é a mais bonita, mas na experiência cotidiana do uso do idioma nativo os mais jovens não utilizam a língua rikbaktsa porque têm vergonha. Athila (2006) relata a preocupação no desuso da língua rikbaktsa pelos mais jovens nas aldeias.

A maior parte dos jovens, crescida e educada nos arredores do Posto missionário Barranco Vermelho, que mais tarde tornar-se-ia aldeia, apesar de compreenderem perfeitamente a língua Rikbaktsa, evitam nela expressar-se. 0 mais preocupante, contudo, é que os filhos destes jovens, de uma maneira geral, não têm sido socializados na língua materna, principalmente aqueles que vivem em famílias nucleares, longe de avós e bisavós. Desta forma, seu contato com o idioma nativo é muito menos constante do que 0 recomendável. Mesmo assim, pude 
gravar alguns cantos, que os tinha gravados com homens mais velhos, entoados por um menino de seis anos de idade (ATHILA, 2006, p. 55).

A língua rikbaktsa constitui a identidade étnica deste povo, e este diferencial é o que caracteriza a sua etnia. Quando os rikbaktsa mais jovens optam por não falar sua língua nativa, eles buscam garantir a oportunidade de incluir-se socialmente, pois, a partir do momento que adquirem o "falar do outro", eles diminuem as pressões sociais resultantes do conflito linguístico existente desde a época da colonização brasileira. Contudo, a vergonha da própria língua pode caracterizar uma negação da etnia rikbaktsa, ou seja, a negação da língua é o meio de inserção e aceitação na cultura do "outro".

Neste contexto, retomamos o conceito de insegurança linguística, "[...] quando os falantes consideram seu modo de falar pouco valorizador e têm em mente outro modelo, mais prestigioso [...]" (CALVET, 2002, p. 72). Neste caso, o modo mais prestigioso é o português, pois há uma competência social nesta abordagem, em que 0 indivíduo se sente valorizado a partir do momento que usa a variedade de mais valor, a inclusão acontece pela apropriação da cultura e do falar do outro, reafirmando que não podemos separar o social do linguístico, já que ambos estão intrinsecamente relacionados. Diante desta perspectiva, perguntamos se existe algum trabalho de preservação da língua rikbaktsa nas aldeias e a maioria respondeu que na escola as crianças têm aula de idioma e podem aprender a língua nativa.

$1.2 \mathrm{H}$ : Hoje tem pessoas que poderiam dar aula indígena dentro da aldeia, [...] se os professores incentivassem essas pessoas para ajudar a juventude e fazer uma roda de conversa no idioma. Meu marido tem interesse de fazer uma roda de conversa e resgatar a cultura e a tradição e eu acho que poderia fazer um resgate cultural.

2.20 M: Mas nós estamos incentivando os professores e os alunos nas escolas para cantar na língua e aprender. No currículo tem as práticas culturais onde todo o fim de semana tem esse trabalho. Na aula de idioma tem as cartilhas.

3.26 M: Tem só os professores que são bilíngues e da aula de idioma na sala de aula para os alunos.

A escola é fundamental na manutenção da língua nativa de um povo, por meio de uma pedagogia que respeita e valoriza a organização social, os costumes e as particularidades da etnia. As atividades pedagógicas devem promover a comunicação na língua nativa e que os conhecimentos adquiridos possam proporcionar aos indígenas o reconhecimento pela sociedade não indígena, garantindo condições de igualdade e autonomia para o povo. Nos rikbaktsa a educação indígena promovida nas escolas das aldeias vem auxiliando a preservação da língua e dos costumes rikbaktsa:

Há escola na maior parte das aldeias, todas com professores exclusivamente indígenas. Observo que muitas destas escolas foram implantadas nas estruturas dos mykyry, que existem em algumas aldeias, com função muito semelhante. Muitos velhos ou indivíduos que não se adaptaram à estrutura dos Postos, pouco falando português, permanecem orientando aqueles mais jovens, com "cantos", "festas", ensinamentos sobre flechas, arte plumária, "histórias" e mitos. "Aulas" como tais podem fazer parte da programação dos professores, embora estas atividades sejam mais propriamente desenvolvidas no mykyry ou nas casas, no contato cotidiano entre aqueles que dominam estas técnicas e os que desejam aprendê-las (ATHILA, 2006, p. 165).

A educação é um mecanismo de preservação da língua rikbaktsa. 0 Referencial Curricular Nacional para as Escolas Indígenas (RCNei, 2008) estabelece que a educação indígena deve favorecer as especificidades de cada etnia, para contemplar a realidade sociocultural de cada povo, sem seguir os modelos estabelecidos pela sociedade indo- 
europeia. Entretanto, muitas escolas indígenas, assim como as escolas rikbaktsa, trabalham com os livros didáticos de nossas escolas regulares. As aulas de geografia, história, matemática etc. são ministradas com os mesmos materiais que são utilizados nas escolas dos centros urbanos. Este tipo de educação não contempla os saberes indígenas e seus costumes. É necessário incentivo do governo para promover 0 desenvolvimento da educação indígena nas aldeias. Há anos que os povos indígenas vêm lutando pela sua legitimação nas aldeias e seu direito de preservar seus costumes por meio da educação.

\section{CONSIDERAÇÕES FINAIS}

De acordo com nossas análises realizadas durante este trabalho, há um processo de deslocamento linguístico, em que 0 português está dominando 0 espaço de propagação da língua rikbaktsa. Entretanto, também existe um processo de manutenção da língua rikbaktsa, por meio das escolas das aldeias, pelo ensino da língua nativa com cartilhas elaboradas pelos próprios professores. Os mais velhos, que falam fluentemente a língua, transmite aos mais novos seus saberes. Os rikbaktsa têm suas particularidades, as quais devem ser abrangidas na educação, pois a cultura deve ser respeitada e voltada aos dizeres de sua etnia e aos anseios da comunidade. Além disso, os rikbaktsa têm a Aimurik (Associação Indígena das Mulheres Rikbaktsa), cujo objetivo é incentivar a cultura e estimular a conservação ambiental, por meio da utilização de materiais da natureza necessários à confecção das peças de artesanato, bem como a utilização de plantas medicinais. Outra associação é a ASSIRIK (Associação Indígena Rikbaktsa), que ajuda os indígenas de maneira geral, buscando recursos para auxiliar as Tls. A preocupação é que esta língua não seja extinta, como tantas outras que já desapareceram ao longo dos anos, como tantas que possuem poucos ou nenhum falante, ou ainda, aquelas línguas indígenas que se foram sem deixar nenhum registro.

\section{REFERÊNCIAS}

ARRUDA, R. S. V. Os Rikbaktsa: mudança e tradição. 1992. Tese (Doutorado em Antropologia) - Pontifícia Universidade Católica de São Paulo, 1992.

ATHILA, A. R. "Arriscando corpos:" permeabilidade, alteridade $\mathrm{e}$ as formas de socialidade entre os Rikbaktsa (Macro-Jê) do sudoeste Amazônico. 2006. Tese (Doutorado em Sociologia e Antropologia) Universidade Federal do Rio de Janeiro, 2006.

BOSW00D, J. Evidências Para a Inclusão do Aripaktsa no Filo Macro-Jê. Série Linguística, Associação Internacional de Linguística - SIL, Anápolis, n. 1, p. 67-78, 1973. Disponível em: <http://www.sil.org/ americas/brasil/publcns/ling/AKMcJe.pdf $>$. Acesso em: 01 out. 2016.

CALVET, L.J. Sociolinguística: uma introdução crítica. São Paulo: Parábola, 2002.

FISHMAN, J. Sociología del Lenguaje. Trad. Ramón Sarmiento y Juan C. Moreno. Madrid: Cátedra, 1995.

GIMENES MORALIS, E. Dialetos em contato: um estudo sobre atitudes Linguísticas. 2000. Disponível em: $\quad<$ http://www.bibliotecadigital.unicamp.br/ document/?code $=v t \mid s 000215182>$. Acesso em:17 out. 2016.

INSTITUTO BRASILEIRO DE GEOGRAFIA E ESTATÍSTICA - IBGE. 2010. Disponível em: <http:// indigenas.ibge.gov.br/estudos-especiais-3/0brasil-indigena/povos-etnias>. Acesso em: 17 out. 2016.

ISA- Instituto Socioambiental. 2014. Disponível em: <https://terrasindigenas.org.br/pt-br/terrasindigenas/3657>. Acesso em: 17. out. 2016.

MEDEIROS, I. A. Inclusão Social na Universidade: Experiências na UNEMAT. Dissertação (Mestrado em Política Científica e Tecnológica) - UNICAMP, 2008.

PACINI, A. Pacificar: Relações Interétnicas e Territorialização dos Rikbaktsa. Dissertação (Mestrado em Antropologia Social) - Universidade Federal do Rio de Janeiro, 1999. 
PACINI, A. Um artífice da paz entre seringueiros e índios. São Leopoldo: Ed. da UNISINOS, 2015.

REFERENCIAL CURRICULAR NACIONAL PARA AS ESCOLAS INDÍGENAS - RCNEI. MEC. Secretaria de Educação Fundamental. Brasília: JB, 2008.

SCHLIEBEN-LANGE, B. História do falar e história da linguística. Tradução de Fernando Tarallo et al. Campinas: Ed. da UNICAMP, 1993.

SILVA, L. J. Aspectos da Fonologia e Morfologia na Língua Rikbaktsa. 2005. Dissertação (Mestrado em Linguística) - Unb, 2005.

WEINRICH, U. Languages in contact: French, German and Romansh in twentieth-century Switzerland. Amsterdam: John Benjamins Publishing Company, 2011.

Recebido em: 23/05/2018

Aceito em: 17/10/2018 